\section{Clinitual âfectures}

DELIVERED AT

\section{CHARING CROSS HOSPITAL.}

$$
\text { BY }
$$

HYDE SALTER, M.D., F.R.S.,

FELLOW OF THE ROYAL COLLEGE OF PHYSICIANS; LECTURER ON PHYSIULOGY AND PaTHOLOGY AT CHARING CROSS HOSPITAL TIEDICAL SCHOOL; AND ASSISTANT. PHYSICIAN TO THE MOSPITAL.

Lecture VIII.-On the Diagnosis of Dropsies.

Importance of the Separate Study of Symptoms. Dropsy a Symptom. Parenchymatous and Cavitary Dropsy. Accumulation not essential to Diopsy. Dropsical Fluxes. Scheme of the Varieties of Dropsy. 1. General Mechanical Dropsy.

2. Local Mechanical Dropsy. 3. Portal Dropsy. 4. Dropsy of Cutaneous ispluyxial Congestion. 5. Dropsy of Chronic Inflammatory Hyperamia. 6. Diopsy of Watery Blood.

Genthemen,-There are several cases of dropsy at the present time in the hospital-two of renal dropsy, two of ascites, one of dropsy of the lower extremities from lung-discase, one of similar dropsy from heart-disease, and one of dropsy of the lower extremities in which neither lung- nor heart-disease exists; and I am anxious to take this opportunity of bringing the subject of dropsy before you in its general bearings.

I think the plan of eliminating some symptom, which several cases, or diseases, possess in common, and considering it by itself apart, has these two advantages-that, in the first place, it brings strikingly before us the points of difference and contrast which the common symptom presents, according as it occurs in one disease or another, and so quickens our perception of the diagnostic value of the different phases and varieties of the common symptom; and secondly, it enables us to "abstract" the essential condition of the symptom, and thus to recognise the presence of the essential condition wherever we find the symptom.

Thus, the comparison of the different forms of dropsy, such as we see it in cardiac, renal, liver, or other disease, reveals to us certain individual peculiarities in each form, and thus imparts to the dropsy itself a diagnostic value in any case in which it may occur. We know that the dropsy of such a disease has such and such characters; when, therefore, we see a dropsy with those characters we know it is the dropsy of that disease. Again, the study of dropsy, in the abstract, enables us to see that the one essential condition on which it depends, whatever may be the disease that gives rise to it, is a state of hypertension of the smaller blood-vessels. It, therefore, acquires this special indicativeness, and whenever we see it we know that this one essential condition exists, and we judge of our patient's state accordingly.

I therefore strongly recommend this method of the study of symptoms to you, and am convinced that unless you study them in this way you will fail to get all the information out of symptoms that they are capable of yielding.
Dropsy, or hydropsy, as it used more correctly to be called, is, as you know, not a disease, but a symptom merely -a symptom of diseases differing most widely from each other. But in former times it was considered a substantive disease, and people used to be said to be sick of the dropsy, and to die of the dropsy, and a most fatal disease it was considered, (the true reason of which we shall see presently, when we come to consider its immediate mechanism). But dropsy is one of those morbid states that the progress of medicine has transferred from the category of diseases to that of symptoms, and those who a hundred years ago died of dropsy now die of heart-disease, or kidney-disease, or liver-disease.

You know that dropsy is an anatomical condition, and that it essentially consists in the accumulation of serum in certain tissues or cavities in which it ought not so to accumulate. When I say "tissues or cavities", I use language not critically correct, and speak of an apparent and not real difference; for dropsy can never accumulate except in cavities; and the difference between that which manifestly accumulates in a cavity, and that which apparently accumulates in a tissue, is, that in the one case the cavity is large, and in the other the cavities are small ; no tissue that does not possess cavities or interspaces is capable of being the seat of dropsy. Thus, in dropsy of the subcutaneous areolar tissue, the seat of the serous accumulation is in tha communicating areolæ or microscopical chambers of that tissue ; and in dropsy of the lungs (cedema i) ulmonum) the serum occupies the cavities of the interlobular areolar tissue and the air-cells. Still, the division of dropsies into "parenchymatous" and "cavitary" is not a bad one ; it is useful and convenient; and, if we bear in mind what I have just said, is not open to the objection of implying any. thing erroneous.

There is one fact that I am anxious to impress upon you,-that the conditions of dropsy may be present, and the process that forms dropsies actually going on, and yet no dropsy may result, because, from the anatomical peculiarities of the part, no accumulation can take place-because the anatomical arrangements are such that as soon as the serum is poured out from the vessels it is discharged on a free or quasi-free surface. For example, we of ten see, in cases in which the circulation to, or through, the liver is obstructed, and in which, as a result of this, ascites has been developed, that there occur occasional, and sometimes almost periodic, serous defluxions from the bowels. The explanation of this phenomenon is this: the obstruction at the portal circulation produces a state of hypertension at all points behind it; that is, throughout the renous portion of the circulation of all the abdominal viscera, as far back as the capillaries. The result of this hypertension is that serous transudation takes place in all the smaller vessels-minute veins and capillaries-which relieve themselves in the first instance, and often only, on the side where there is least resistance, namely into the free cavity of the peritoneum. Sometimes, however, in addition to this, they relieve themselves through the mucous membrane of the alimentary tube, and the serum thus poured into the bowel is discharged by stool. But such a serous discharge is not a whit the less a dropsical effusion because it is poured out on a free surface; it is exactly of the same significance, due 
to the same cause, and points to the same state of the abdominal circulation, as the accumulation in the peritoneum. Just in the same way, albuminuria in heart-disease is simply dropsy occurring at the kidney ; it is the exact correlative phenomenon of the œedema of the lower extremities. In the legs, the effused serum finds itself in a network of chambers, shut in by the skin, from which it cannot escape, and in which it, therefore, accumulates; while, in the kidney, the serum finds itself in a system of tubes terminating by open mouths in the calyces, and down these tubes, mingling with the water and other elements of the urine, it trickles, and so into the calyces, pelvis of the kidney, ureter, bladder: the urine is voided; we examine it, and by the ordinary re-agents render visible the albumen of the serum, and we call it albuminuria. But it no more points to the kidneys than the odema points to the legs; still less does it imply anything amiss with the urine. It simply says that all the vessels tributary to the inferior cava feel the obstruction at the heart. That the serum is voided with an excretion instead of shut up in a tissue is a mere accident of anatomy; the essential condition is dropsy at the kidney.

In such an example as the one I have just cited there naturally exists the same state of things as exists in an œdematous leg after acupuncture has been performed on it. In such a leg, the swelling goes down, and as long as the acupuncture wounds are open, does not re-appear; but the condition of the circulation is just what it was before-there is the same vascular tension and the same dropsy-forming transudation, as is shown by the constant drain from the orifices; and, as far as the diagnostic and prognostic indications of dropsy go, the state of things is just the same as if the legs were the seat of any amount of œdema.

Remember then that such serous discharges as I have spoken of possess the significance of dropsy, and nothing more.

The best arrangement of the varieties of dropsy that I have been able to devise, is what you see in

\begin{tabular}{|c|c|c|}
\hline $\begin{array}{l}\text { Tarieties of } \\
\text { dropsy. }\end{array}$ & Symptoms. & $\begin{array}{l}\text { Diseases in which } \\
\text { they occur. }\end{array}$ \\
\hline 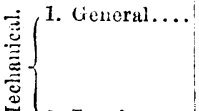 & $\begin{array}{l}\text { Subcutaneous cdema, be- } \\
\text { ginning at the feet, and } \\
\text { becoming more and more } \\
\text { universal. 1)ropsy of ca- } \\
\text { vities at last. Dijsmara. }\end{array}$ & $\begin{array}{l}\text { Chronic bronchi- } \\
\text { tis. Valvular dis- } \\
\text { ease of the heart. }\end{array}$ \\
\hline$\Rightarrow$ 2. Local.. & $\begin{array}{l}\text { Partial subcutaneous drop- } \\
\text { sy of upper extremities, } \\
\text { or lower. Other paits per- } \\
\text { fectly free. Dyspuca not } \\
\text { necessarily present. }\end{array}$ & $\begin{array}{l}\text { Abdominal tumrs. } \\
\text { Pressure of aneu- } \\
\text { rism on sup. cava. } \\
\text { Phlegmasia do- } \\
\text { lens. }\end{array}$ \\
\hline 8. Portal dionsy .. & $\begin{array}{l}\text { Ascites. No dyspruce. No } \\
\text { other dropsy. Nymptoms } \\
\text { of liver disease generally } \\
\text { present. }\end{array}$ & Cirrhosis. \\
\hline $\begin{array}{l}\text { 4. Dropsy of cuta- } \\
\text { neous asphyx } \\
\text { iul congestion }\end{array}$ & $\begin{array}{l}\text { Universal subcutancous } \\
\text { œdema, beginnin! vory } \\
\text { often at the face. No } \\
\text { dyspncer necessarily pre- } \\
\text { sent(?). Nlbuminulia. }\end{array}$ & $\begin{array}{l}\text { Bright's disease. } \\
\text { Acute dropsy from } \\
\text { cold, and afier } \\
\text { scarintina. }\end{array}$ \\
\hline $\begin{array}{l}\text { 5. Dropsy of chro- } \\
\text { nic inflanma- } \\
\text { tory hyperæmia }\end{array}$ & $\begin{array}{l}\text { The insidious accumulation } \\
\text { of fluid in a serous eavity, } \\
\text { without notalie pain. }\end{array}$ & $\begin{array}{l}\text { Hydrothorax. Stru- } \\
\text { mons ascites of } \\
\text { children. Hydro- } \\
\text { ce!o, etc. }\end{array}$ \\
\hline $\begin{array}{l}\text { 6. Dropsy of watery } \\
\text { bluod } \ldots \ldots \ldots\end{array}$ & $\begin{array}{l}\text { P'allor; breath!essiness on } \\
\text { exertion; faintness; pal- } \\
\text { pitation; vertigo; Ame- } \\
\text { norrhoa; face and upper } \\
\text { extremities puffy; Jower } \\
\text { extremities odematous. }\end{array}$ & $\begin{array}{l}\text { Chiorosis. Flood- } \\
\text { ing, etc. }\end{array}$ \\
\hline
\end{tabular}

this table. It does not perfectly satisfy my mind; for I have been obliged to make, in one point, a sacrifice of systematic exactness for the sake of clearness and utility, as I shall presently explain ; still it is the best I have to offer you. It is on the correct recognition of the characteristics of these varieties that the diagnosis of dropsy depends, and, therefore, such a table as this may be said to repre.sent the whole subject of the diagnosis of dropsy.

The first two varieties of dropsy, you see, I call "mechanical"; the rest, not. I do this in obedience to general custom. But it is a distinction that does not represent an essential difference. Some forms of the so-called mechanical dropsies are not more mechanical, in the way in which they are produced, than others that are not so named. The dropsy of heart-disease and chronic bronchitis are both called mechanical dropsies, and depend, one on an impediment established at the heart, the other on an impediment established at the lungs; which impediment, in each case, retrogrades upon the systemic venous system, and, ultimately reaching the peripheral vessels, gives rise to transudation and dropsy. But the universal anasarca of acute dropsy from exposure to cold is just as mechanical in its cause, and just as dependent on an impediment established at a certain part of the circulation, as the dropsy of chronic bronchitis. The one is due to stasis at the capillaries of the lungs, the other to stasis at the capillaries of the skin: in the one, the impediment retrogrades a long way before it reaches the point where it produces the dropsy; in the other, the dropsical transudation takes place immediately behind, one might almost say at, the point of arrest. But both are equally mechanical; both are dependent on an asphyxial capillary stasis-the one of the lungs, the other of the skin.

A far better, or rather a far more exact, arrangement would be to divide dropsies into those that are produced by an obstruction placed on some main vessel, and those that are due to peripheral or capillary impediment. Of the first class would be the dropsy from heart-disease, that from the pressure of ancurismal or other tumour on the superior or inferior cava, the ascites from pressure on the venc portce, the cdema of a leg from plugging of its main vein, etc. Of the second class would be the dropsy of chronic bronchitis, the ascites of cirrhosis, the anasarca of acute dropsy, the serous collections resulting from hyperæmias of an inflammatory type, as hydrothorax, chronic hydrocephalus, the ascites of struma. But, though this would be the more exact, I think the arrangement I have adopted is the more practically useful, because it is based, not on etiology, but on a natural grouping of wellmarked clinical phenomena, and is therefore a diagnostic arrangement. Let me now give you a short running commentary on my table.

The first variety-"General Mechanical"-is the commonest of all forms of dropsy, and is that which attends the closing scene of so many cases of heart and lung disease. It is always chronic, has always been preceded by the well-marked symptoms of thoracic disease, especially is dyspncea sure to have been present, and generally urgent; if due to heartdisease, the dyspnoa may have been much less marked than if due to lung-disease. But it is impossible for either heart or lung disease to generate dropsy without the intervention of dyspncea ; ergo, any case of dropsy in which all trace of dyspnoa is, 
and has been, clearly absent, is not dropsy of this kind-is not dependent on heart or lung disease. This form of dropsy is, in its distribution, more affected by gravitation than any other; it always begins at the feet, and change of position for a single night will throw it from one arm and hand to the other ; it attains a development more enormous than any other form, and in its last stages is frequently complicated with local purpurous hamorrhage.

The second variety-" Local Mechanical"-is characterised by its partial distribution, and by that distribution corresponding with some separate segment of the venous system, and not being affected by gravitation; all other parts of the body being perfectly free from any tendency to dropsy. We see examples of it in œdema of the legs from pressure of an abdominal tumour on the inferior cava, of one leg from that of a pelvic tumour on one of the iliacs, in the swollen face and arms from pressure of an aneurismal or other tumour on the superior cava, in local œdema from venous plugging, etc. Dyspnœa may be present, or it may not. The great characteristic of this dropsy is its partialness and immobility, and the perfect freedom of all other parts from any trace of dropsical tendency.

Variety the third-" Portal Dropsy"-is no doubt the weak point of my scheme, for it includes dropsies that might correctly fall under other heads, and it unites those that are essentially distinct. For example, ascites from pressure of a tumour on the portal vein as it enters the liver is "local mechanical dropsy", and should come under variety the second; and such dropsy has no more alliance with ascites dependent on cirrhosis than dropsy from an intrathoracic tumour has with dropsy from chronic bronchitis; - the one is dropsy from pressure on a main vessel, the other from multitudinous capillary arrest. Still, the one characteristic and essential symptomascites, unattended with other dropsy-is so striking a clinical phenomenon, and having such certain and precise diagnostic indicatious, that I have thought it well to erect this form of dropsy into a separate variety. Its characteristic signs are the well known physical signs of ascites-general abdominal distension with a material freely obeying the laws of gravitation, dull at the most dependent parts, resonant at the top, and imparting the characteristic thrill and wave on percussion. If such a condition is present, and all other dropsical symptoms are absent, we may be sure, whether there are signs of liver-disease or not, that the one thing pointed to is portal impediment of some kind or other.

The fourth variety-dropsy from what I call " $\mathrm{Cu}$ teneous Asphyxial Congestion"-characterises a perfectly natural group of cases. It is generally sudden in its appearance, often the first warning of illness, is universal in its distribution, is affected but very slightly by gravitation, often appears first in the face, is frequently quite unaccompanied by dyspnœa or coush, is always attended with albuminuria, sometimes with hrmaturia, and has gencrally been preceded by some cause of suppression, oi morbid condition, of the function of the skin. We see examples of such dropsy in the dropsy after scarlatina, in the different forms of Bright's disease, and in simple acute dropsy from exposure to cold. With regard to the theory of this dropsy, I will at present say no more than that I believe it depends on a state of the capillaries of the skin similar to that of the capillaries of the lungs in asphyxia-a state of congestion or stasis from the blood not being depurated of that of which it ought to be freed in that particular capillary system, and therefore not in a state to leave that capillary system.

I have my doubts as to the legitimacy of calling the dropsies of the fifth variety true dropsies; they doubtless pass by imperceptible degrees into cases of genuine serous inflammation-cases of true pleurisy, peritonitis, etc. Still they are often so free from all symptoms of inflammation, and are so closely allied to non-inflammatory dropsies, that it would be diffcult to draw the line between them. Hydrocele may be taken as a good example of this kind of dropsy, and that peculiar insidious form of hydrothorax in which the first thing that makes the patientaware that anything ails him is the discovery that he has a pleura full of fluid. The distinctive features of dropsy of this kind are-that it is always cavitary (necessarily), affecting some single serous sac; that it occurs apparently spontaneously; and that there is a clear absence of all those conditions to which secondary or symptomatic dropsy is attributable.

The sixth variety is the Dropsy of Extreme Ancenia. We sometimes see it in chlorosis, and we especially see it after profuse hæmorrhages. I think I have seen it the most marked in women who have flooded. It is a form of dropsy vastly commoner in women than in men-indeed, it is very rare to see it in men; but I have seen it in two or three cases in men who have lost a great deal of blood from hæmorrhoids. It was conspicuously marked in the case of Thos. Spurritt, who is now lying in bed No. 5 of the Clinical Ward, and who, you know, has lost an incalculable quantity of blood from chronic ulceration of the lower bowel. His face was so puffy when he came into the hospital, that one could not resist the impression that he was suffering from renal dropsy. We found, however, that such was not the case. $\mathrm{He}$ has had no bleeding for five weeks, and the puffing of the face is almost gone. As anæmia, to induce this dropsy, must be extreme, the signs of anæmia are so strongly marked as to enable one to identify it at once. Moreover, except when it arises from chlorosis, there is almost always the antecedent circumstance of the hæmorrhage to guide one; and there is also, as in the preceding variety, the absence of all the ordinary causes of dropsy-there is no heart-disease, no lung-disease, no liver-disease, no kidney-disease. This dropsy is never cavitary.

Let us now proceed to the analysis of the cases of dropsy at present in the hospital, and see how we shall be able to diagnose each case on the strength of the peculiar features of the dropsy that characterises it.

[To be concluded.]

Vacancies. The following appointments are vacant; Assistant-physician at King's College Hospital; actingphysician and acting-surgeon to the Birmingham and Midland Free Hospital for Sick Children; two surgeons to the Islington Dispensary ; medical officer and general superintendent to the Dundee Royal Infirmary; resident medical officer to the Leeds Fever Hospital; house-surgeon to the West Norfolk and Lynn Hospital; housesurgeon to the Chester General Infirmary; assistantsurgeon to University College Hospital ; and physician's assistant and junior house-surgeon to the Manchester Royal Infirmary and Dispensary. 